Provided for non-commercial research and education use. Not for reproduction, distribution or commercial use.

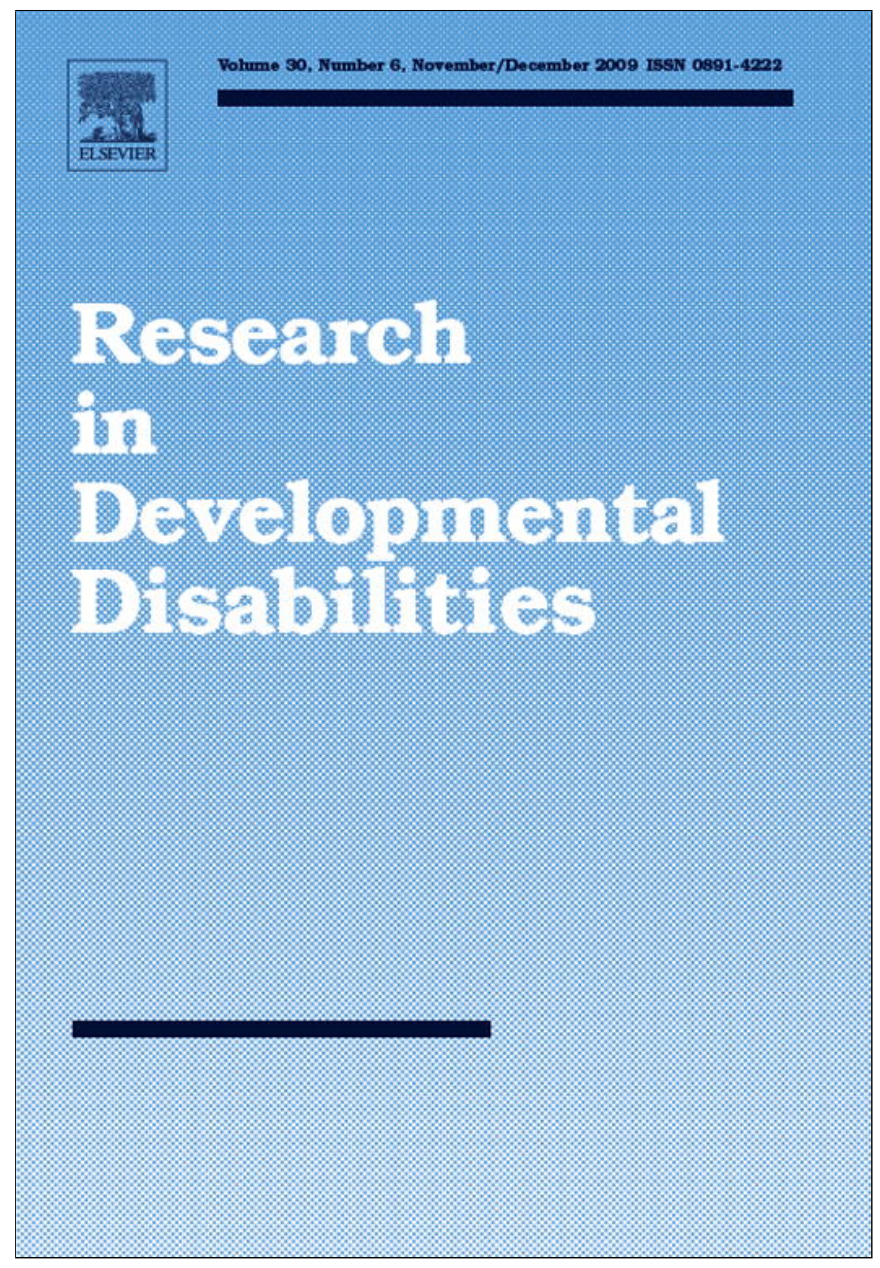

This article appeared in a journal published by Elsevier. The attached copy is furnished to the author for internal non-commercial research and education use, including for instruction at the authors institution and sharing with colleagues.

Other uses, including reproduction and distribution, or selling or licensing copies, or posting to personal, institutional or third party websites are prohibited.

In most cases authors are permitted to post their version of the article (e.g. in Word or Tex form) to their personal website or institutional repository. Authors requiring further information regarding Elsevier's archiving and manuscript policies are encouraged to visit:

http://www.elsevier.com/copyright 


\section{Usefulness of the Supports Intensity Scale (SIS) for persons with other than intellectual disabilities}

G. Bossaert ${ }^{\mathrm{a}, *}$, S. Kuppens ${ }^{\mathrm{b}}$, W. Buntinx ${ }^{\mathrm{c}}$, C. Molleman ${ }^{\mathrm{d}}$, A. Van den Abeele ${ }^{\mathrm{d}}$, B. Maes ${ }^{\mathrm{a}}$

${ }^{a}$ Centre for Parenting, Child Welfare and Disabilities, K.U.Leuven, Belgium

${ }^{\mathrm{b}}$ Centre for Methodology of Educational Research, K.U.Leuven, Belgium

${ }^{\mathrm{c}}$ Governor Kremers Center, Maastricht University, The Netherlands

${ }^{\mathrm{d}}$ Flemish Agency for Persons with a Disability, Belgium

\section{A R T I C L E I N F O}

\section{Article history:}

Received 20 May 2009

Accepted 21 May 2009

\section{Keywords:}

Support needs

Disability

Reliability

Validity

Assessment

\begin{abstract}
A B S T R A C T
In response to the shift from a system-centred care model to a person-centred support model, the Supports Intensity Scale (SIS) has been developed as an instrument to assess the support needs of persons with intellectual disabilities. The instrument is used as a tool for constructing individual support plans, as well as a tool for resource allocation. The aim of the present study was to evaluate the usefulness of the SIS for persons with other than intellectual disabilities. Therefore, the psychometric properties of the SIS were investigated in a sample of 1303 persons with other than intellectual disabilities. Confirmatory factor analysis failed to support the originally proposed six-factor model within this sample. However, an explorative examination of the underlying structure resulted in a shortened version of the SIS, including four subscales and 22 items. Further analyses revealed satisfying results for reliability, construct validity, and criterion validity of the shortened assessment tool (SIS-NID).
\end{abstract}

(c) 2009 Elsevier Ltd. All rights reserved.

For several years now, a paradigm shift has changed the way people with disabilities are perceived. Whereas the focus was previously on the nature of the individuals' impairments and associated deficits, people with disabilities are now viewed as "people who have a life and need support" (Butterworth, 2002, p. 85). Support has been defined as "the resources and strategies that aim to

\footnotetext{
* Corresponding author at: K.U.Leuven, Centre for Parenting, Child Welfare and Disabilities, Andreas Vesaliusstraat 2, P.O. BOX 3765, B-3000 Leuven, Belgium. Tel.: +32 163259 40; fax: +32 16325933.

E-mail address: goele.bossaert@ped.kuleuven.be (G. Bossaert).
} 
promote the development, education, interests, and personal well-being of a person and that enhance individual functioning" (Luckasson et al., 2002, p. 151; Thompson et al., 2009, p. 135).

This shift from a deficit-oriented towards a support-based model in which full participation in society and self-determination are central components, has major implications for the organization of disability services. Ideally, the supports of each client should be person-centred, or tailored to the specific needs, competencies and preferences of the person with disabilities and his/her social network. This requires the development of new systems of classification and support implementation as well as changes in resource allocation and financial planning (Thompson et al., 2002). So far, international discussion has focused on (i) the cost of service provision and the identification of factors that impact on the cost and quality of services; (ii) advantages and disadvantages of individual versus service-based payments; (iii) resource modeling, trying to achieve equity and rationality in resource allocation; and (iv) measurements of need, including developing procedures for prioritizing limited resources (Guscia, Harries, Kirby, Nettelbeck, \& Taplin, 2006).

In response to the need to objectively assess a person's support needs in medical, behavioral and life activities, Thompson et al. (2004) developed the Supports Intensity Scale (SIS). According to the authors, the SIS can be used as an individual planning tool or as a tool for resource allocation. Nowadays, the instrument is widely used by service providers as well as governmental agencies. It has been translated in several languages, such as French, Italian, Catalan, Complex Chinese, Spanish, Hebrew, and Dutch (Schalock, Thompson, \& Tassé, 2008).

Evidence on the psychometric properties of the original SIS (Harries, Guscia, Kirby, Nettelbeck, \& Taplin, 2005; Thompson et al., 2004; Thompson, Tassé, \& McLaughlin, 2008) as well as of the translated versions, such as the French (Lamoureux-Hébert \& Morin, 2008; Morin \& Cobigo, 2008), Spanish (Giné, 2008; Verdugo, Arias, Ibanèz, \& Gómez, 2006), and Dutch (Buntinx, 2006, 2007, 2008a, 2008b; Buntinx, van Unen, Speth, \& Groot, 2006; Kuppens et al., submitted for publication; Maes, Bossaert, Kuppens, \& Buntinx, 2008) version, has cumulated over the past years. As the SIS has been developed to measure support needs of persons with intellectual disabilities, reliability and validity indices have primarily been studied within this target group. However, the conceptual properties of the 'support' construct suggest relevance for other groups as well (Thompson et al., 2009). Accordingly, the SIS may present a relevant instrument beyond the original target group.

Although the authors have invited researchers to examine the SIS with different disability groups (Guscia et al., 2006), so far only one study has actually probed the SIS with other target groups. Guscia et al. (2006) studied the construct and criterion validity of the SIS in a group of 31 persons with a physical or neurological disability or acquired brain injury as the primary disability. Results of this study offered support for the use of the SIS for individuals without a primary intellectual disability. However, given the small sample and the diversity of disabilities within the sample, these results can merely be seen as preliminary evidence, which may not generalize to the entire population of persons with other than intellectual disabilities (e.g., physical, sensory, acquired brain injury, or autism). Hence, the main goal of the present study was to thoroughly examine the psychometric properties of the SIS in a large sample of persons with physical or sensory disabilities, autism, psychiatric disorders or acquired brain injury. Four research questions guided the present study. First, this study examined the factor validity of the SIS support needs section for persons with other than intellectual disabilities. In line with previous research on the factorial validity of the SIS support needs section for persons with intellectual disabilities (Kuppens et al., submitted for publication), we expected to find support for the multidimensional structure of the support needs construct as promulgated by the authors. This multidimensional construct comprises six subdomains namely home living activities, community living activities, life long learning activities, employment activities, health and safety activities, and social activities. Second, reliability of the resulting subdomains was studied for persons with other than intellectual disabilities. In line with both the English (Thompson et al., 2004) and the Dutch manual (Buntinx, 2006), high internal consistency within the six subdomains was expected. Referring to the psychometric properties mentioned in the English and Dutch manual, we expected adequate inter-item correlations and item-rest correlations for all items within each of the six subdomains. Furthermore, we did not expect that internal consistency values would increase by removing individual items which further supports the internal consistency of the six subdomains. Third, construct validity was examined for persons with other than intellectual disabilities. Based on previous research, construct validity was expected to be reflected by medium to 
Table 1

Participant characteristics $(N=1303)$.

\begin{tabular}{|c|c|c|}
\hline Variable & $N$ & $\%$ \\
\hline \multicolumn{3}{|l|}{ Gender } \\
\hline Male & 802 & 61.55 \\
\hline Female & 500 & 38.37 \\
\hline Unknown & 1 & 0.00 \\
\hline \multicolumn{3}{|l|}{ Age group } \\
\hline 20-50 years & 830 & 63.70 \\
\hline$>50$ years & 472 & 36.22 \\
\hline Unknown & 1 & 0.00 \\
\hline \multicolumn{3}{|l|}{ Disabilities } \\
\hline Acquired brain injury & 623 & 47.81 \\
\hline Sensorial disability & 95 & 7.29 \\
\hline Physical disability & 186 & 14.27 \\
\hline Psychiatric disorder or severe behavioral disorders & 39 & 2.99 \\
\hline Autism spectrum disorder & 125 & 9.59 \\
\hline Sensorial + physical disability & 52 & 3.99 \\
\hline Sensorial and/or physical disability and psychiatric disorder & 70 & 5.37 \\
\hline Sensorial and/or physical disability and other disabilities & 107 & 8.21 \\
\hline Other combinations & 6 & 0.00 \\
\hline \multicolumn{3}{|l|}{ Services for person with disabilities } \\
\hline \multicolumn{3}{|l|}{ Work } \\
\hline Services for supported employment (working) & 56 & 4.30 \\
\hline Day care centre (not working) & 365 & 28.01 \\
\hline \multicolumn{3}{|l|}{ Living } \\
\hline Services for supported living & 223 & 17.11 \\
\hline Community homes & 62 & 4.76 \\
\hline Group homes for working individuals & 35 & 2.69 \\
\hline Group homes for not working individuals & 188 & 14.43 \\
\hline Nursing homes & 357 & 27.40 \\
\hline
\end{tabular}

high positive association between the subscales (e.g., Thompson et al., 2004), a large positive association between support needs and adaptive behavior as assessed by the Barthel Indices and the ELIDA (e.g., Guscia et al.,2006; Harries et al., 2005; Thompson et al., 2002), and a positive association between support needs and the need for behavioral support (e.g., Guscia et al., 2006) reflected by the correlations between the SIS subscales of section 1 and the SIS section measuring behavioral problems. Fourth, criterion validity of the support needs constructs was evaluated. A positive association between supports needs and the support services type was hypothesized, indicating that persons within more intensive support services, regarding working as well as living (see Table $1^{1}$ ), receive a higher level of support needs (as reflected by the sum of the subscales). For example, we expected that the support needs pertaining to working would be higher for persons served within a non-working facility (e.g., day care centre) than for persons within a service for working persons (e.g., service for supported employment). Regarding living, we expected that the support needs of persons served within a nursing home would be higher compared to the support needs of persons, assessed within group homes for not working persons, group homes for working persons, community homes and within a service for supported living.

\section{Method}

\subsection{Participants}

The present data were part of a larger project conducted by the Vlaams Agentschap voor Personen met een Handicap (VAPH) [Flemish Agency for Persons with a Disability]. The VAPH subsidizes

\footnotetext{
${ }^{1}$ Table 1 displays the different types of support services, currently available in Flanders, sorted by increasing level of intensity.
} 
services, ranging from supported employment to nursing homes, for all people with a disability in the Flemish speaking part of Belgium. The VAPH defines a disability as "any long-term and significant participation problem experienced by a person and attributable to a combination of functional disorders of a mental, psychic, physical or sensory nature, limitations in the performance of activities, and personal and external factors" (Vlaams Agentschap voor Personen met een Handicap, n.d., 2009). In 2006, the VAPH administered a large-scale assessment of support needs among all clients known by the agency. Information was gathered on 16,860 individuals with disabilities. The sample of the present study includes 1303 individuals with other than intellectual disabilities. They ranged in age from 20 to 86 years $(M=44.99 ; S D=13.81)$; approximately $62 \%$ were male. Almost half of the individuals with other than intellectual disabilities were suffering from an acquired brain injury (47.81\%). Approximately thirty-four percent (34.15\%) of the individuals with other than intellectual disabilities had either a sensorial disability, a physical disability, a psychiatric disorder or severe behavioral disorders, or was diagnosed with an autism spectrum disorder. The remaining 235 individuals (18.04\%) had multiple disabilities. The majority $(66.39 \%)$ of the individuals with other than intellectual disabilities were enrolled in a service for living, ranging from services for supported living to a nursing home, whereas approximately one third (32.31\%) of the individuals were registered in a service for supported employment or a day care centre. Detailed participant characteristics are shown in Table 1.

\subsection{Procedure}

Within each facility or service, the Dutch version of the Supports Intensity Scale (SIS-NL 1.0) (Buntinx, 2006) was administered by a professional in the human services field, in consultation with at least one (75\%) or two (62\%) members of the direct support workers or the family. Most interviewers were certificated Master's degree in Psychology or Educational Sciences (41\%) or Professional Bachelors in Social Work (42\%). Interviewers held the position of pedagogue or psychologist (35\%), direct support worker (17\%), house manager (15\%), social worker $(10 \%)$, service coordinator $(5 \%)$ or other (5\%). There was no information available concerning the education level or role of the remaining interviewers. In most cases interviewers and respondents had known each other for several years. In less intensive care services (21\%) as well as for most persons with acquired brain injury, participants were also involved in the assessment process. Services obtained the SIS-scores for each individual. Furthermore the VAPH send out two feedback forms to all agencies comprising quantitative and qualitative results for the total sample of the VAPH.

During the data collection, the official manual of the translated version of the SIS was not yet available and the project's time frame (July 2005-January 2006) did not permit the researchers to provide extended training sessions to all services. Therefore, four measures were taken to enhance the data quality. First, a booklet including more detailed instructions, specifically designed for the project, was sent to the interviewers. Group-wise training sessions were provided within each Flemish province, which were attended by at least one employee of about $80 \%$ of the services. Furthermore a group of coaches was available to answer questions over the telephone, and answers to Frequently Asked Questions were collected on the website of the VAPH.

Moreover, additional information about the support needs of individuals (53\%) in intensive care services was collected. Staff were asked to complete two frequently used adaptive behavior scales in Flanders: the Barthel Index (De Haan et al., 1993) and the ELIDA scale (Brusselmans, 1992).

\subsection{Instrumentation}

The Supports Intensity Scale (SIS) has been developed to evaluate the support needs of individuals with an intellectual disability in medical, behavioral, and life activities (Thompson et al., 2004). The first section of the scale is comprised of 49 items on support needs concerning life activities organized into six subscales, namely home living activities (e.g., using the toilet), community living activities (e.g., going to visit friends and family), lifelong learning activities (e.g., interacting with others in learning activities), employment activities (e.g., learning and using specific job skills), health and safety activities (e.g., taking medications) and social activities (e.g., socializing within the household). 
The items are rated on a 5-point scale with regard to frequency $(0=$ none or less than monthly; 1 = monthly; 2 = weekly; 3 = daily; 4 = every hour $)$, daily support time $(0=$ none; $1=$ less than 30 min; 2 = between $30 \mathrm{~min}$ and $2 \mathrm{~h} ; 3=$ between 2 and $4 \mathrm{~h} ; 4=4 \mathrm{~h}$ or more), and type of support $(0=$ none; $1=$ monitoring; 2 =verbal or gestural prompting; 3 = partial physical assistance; $4=$ full physical assistance). For each subscale in this sample, there are strong correlations $(p<.001)$ between the ratings on frequency, daily support time, and type of support (range $r_{\text {frequency, daily support time }}=.58-.81$; range $r_{\text {frequency, type of support }}=.54-.90$; range $r_{\text {daily support time, type of support }}=.79-.90$ ). Item scores are obtained by summing the ratings on frequency, daily support time, and type of support per item. Subsequently the item scores are summed into a subscale score. Subscale scores are transformed to yield standard scale scores. Finally, standard scale scores can be converted into a Support Needs Index. The instrument also includes supplementary sections regarding protection and safety and exceptional behavioral and medical support needs. Analogous to former publications (e.g., Harries et al., 2005), only the first section, labeled support needs, was included in this study. Adequate psychometric properties have been demonstrated for the original and the Dutch translated version of the SIS support needs section for people with intellectual disabilities (Buntinx, 2006; Kuppens et al., submitted for publication; Thompson et al., 2004, 2008).

The Barthel Index (BI) is an adaptive behavior scale, which was developed in 1965 (Mahoney \& Barthel, 1965) and was later modified by Granger and colleagues (Granger, Devis, Peters, Sherwood, \& Barrett, 1979). The BI provides separate scores for the activities of daily living, mobility and an overall rating of independence. High scores on the BI reflect a higher level of independence. According to Van der Putten, Hobart, Freeman, \& Thompson (1999), the reliability and validity of the BI has been demonstrated in several studies. The instrument was translated into Dutch by De Haan et al. (1993). In this study, a slightly adapted version of the Dutch translation was used. All, except two items were scored on a 5 -point Likert scale ranging from $1=$ yes, without help to $5=$ no, completely dependent. Two items on controlling bowels/bladder were scored on a 3-point scale ( $a=$ independent, $\mathrm{b}=$ accident less than once a week, $\mathrm{c}=$ accident more than once a week).

The ELIDA-scale or Estimation of Loss of Independence-scale (Brusselmans, 1992) is an adaptive behavior scale which measures the need for assistance in daily living activities. Fifty activities, within 10 subscales are rated on a yes/no basis. Higher scores reflect a higher need of assistance. The scale was validated in comparison with the Functional Independence Measure for people with acquired brain injuries and was also found to be reliable (Brusselmans, 1993).

\subsection{Analysis strategy}

First, confirmatory factor analysis was conducted to test the originally proposed six-factor structure of the SIS in the present sample. This six-factor model was compared to a single-factor model, because previous research revealed strong correlations between the subscale scores of persons with intellectual disabilities (e.g., Buntinx, 2006; Thompson et al., 2004). The LISREL 8.72 (Jöreskog \& Sörbom, 2005) software package was employed to conduct confirmatory factor analyses for ordinal data using robust maximum likelihood estimation, which resulted in Satorra-Bentler-Scaled- $\chi^{2}$ statistics. However, because $\chi^{2}$ statistics are highly sensitive to large sample sizes, multiple alternative goodness-of-fit statistics were used to assess the models' fit: Root-Mean-Square Error of Approximation (RMSEA), Comparative Fit Index (CFI), and Standardized Root-Mean-Square Residual (SRMR). RMSEA-values less than .06, CFI-values equal or higher than 0.95 and SRMR-values equal or lower than 0.08 are usually considered as indicating adequate fit (Hu \& Bentler, 1999). If confirmatory factor analysis fails to support the proposed factor structure, an exploratory factor analysis will be conducted.

Second, as a measure of reliability, Chronbach's alpha was used to examine the internal consistency of the subscales. Furthermore, for each subscale item-rest correlations, and Chronbach-alpha-if-itemdeleted were computed and the lowest acceptable values for Cronbach's alpha and item-rest correlations were set at .70, and .20, respectively (Nunnally \& Bernstein, 1994). The inter-item correlations were also calculated and results between .20 and .40 were considered the lowest acceptable values (Nunnally \& Bernstein, 1994). Pearson correlations were used to examine construct validity and criterion validity was examined by means of Eta which reflects correlations between a 
categorical (i.e., the type of service provided) and a quantitative variable (i.e., the sum of the SIS subscales). According to Cohen (1988) correlations between .10 and .30 are small, between .30 and .50 are medium, and higher than .50 are large.

Additionally, given the diversity of disabilities within the sample of persons with other than intellectual disabilities, reliability and validity analyses were conducted for several subgroups. In order to be able to make clear distinctions between subgroups, multiple disabilities were not allowed. As such, four subgroups were created, namely persons with acquired brain injury, persons with sensory disabilities, persons with physical disabilities, and persons with autism spectrum disorder (see Table 1).

The SPSS 15.0 software package for Windows (SPSS Inc., Chicago, IL, USA), was used throughout the analysis phase, except for confirmatory factor analyses.

\section{Results}

\subsection{Factorial validity}

\subsubsection{Confirmatory factor analysis}

The six-factor model as promulgated by the authors of the SIS-instrument did not provide an adequate fit to the data, SBS- $\chi^{2}(1112)=11767.19$, RMSEA $=.091, \mathrm{CFI}=.975, \mathrm{SRMR}=.079$, neither did the competing single-factor model, SBS- $\chi^{2}(1127)=34560.72$, RMSEA $=.160$, CFI $=.920$, SRMR $=.095$, as indicated by poor goodness-of-fit-indices.

\subsubsection{Exploratory factor analysis}

Because the a priori structure of the SIS was not confirmed in the present sample of persons with other than intellectual disabilities, an explorative approach was taken to examine the underlying structure. A principal axis factor analysis with PROMAX rotation, allowing for correlations between factors, was used. Items with primary factor loadings above 0.60 and secondary factor loadings below 0.35 were retained. Because the Kaiser's criterion (i.e., eigenvalue-greater-than-one) suggested a fourfactor solution and the scree test procedure suggested a two-factor solution, both solutions were explored.

The two-factor solution explained 59.98\% of the variance. The first factor entailed almost all items (except B7) from the subscales 'home living activities' and 'community living activities' and one item of the subscale 'health and safety activities' (i.e., E4) concerning mobility. The second factor consisted of specific items from the subscales 'lifelong learning activities' (i.e., C2, C3, C7, C8, C9), 'employment activities' (i.e., D3, D4, D7, D8), 'health and safety activities' (i.e., E6, E8) and 'social activities' (i.e., F1, F4, F5, F6, F7). Most items of the second factor probed communication and relational skills (e.g., communicating and cooperating with colleagues). In addition, the scale included some items assessing personal skills (e.g., learning self-determination skills).

The four-factor model explained $70.20 \%$ of the variance. Based on the more delineated content of the factors and the amount of explained variance, the four-factor model was preferred. In this model, 22 items were retained. The first factor consisted of eight items labeled 'Personal and social skills'. This factor included items of the original SIS-subscales 'lifelong learning activities' (i.e., C8, C9), 'health and safety activities' (i.e., E8) and 'social activities' (i.e., F1, F4, F5, F6, F7) and mainly considers communication and relational skills (e.g., communicating personal needs), and some personal skills (e.g., learning self-determination skills). The second factor was labeled 'Community living activities' (seven items) and includes all items, except one (B7), of the original SIS subscale 'community living activities'. The third factor comprised items (i.e., A1, A4, A6, A7) from the original SIS subscale 'home living activities' and was labeled 'Activities for daily living' (four items). The fourth factor entailed three items (i.e., D2, D5, D6) from the original SIS-subscale 'employment activities' and was labeled 'Work' pertaining to work-related support needs (Table 2).

Because almost half of the sample included persons with acquired brain injury (see Table 1), exploratory factor analysis were also conducted for persons with acquired brain injury and persons with other disabilities separately. Factor solutions were highly similar in both groups. 
Table 2

Factor loadings for the four extracted factors using PROMAX rotation.

\begin{tabular}{|c|c|c|c|c|}
\hline & F. 1 & F. 2 & F. 3 & F. 4 \\
\hline \multicolumn{5}{|l|}{ Personal and social skills $(\alpha=0.93)$} \\
\hline C8 learning self-determination skills & .83 & -.05 & -.00 & .06 \\
\hline C9 learning self-management strategies & .79 & -.04 & -.01 & .09 \\
\hline E8 maintaining emotional well-being & .75 & -.04 & -.02 & .05 \\
\hline F1 socializing with the household & .78 & -.01 & .04 & -.01 \\
\hline F4 making and keeping friends & .70 & .22 & .02 & -.04 \\
\hline F5 communicating with others about personal needs & .83 & .03 & .04 & -.05 \\
\hline F6 using appropriate social skills & .78 & -.04 & .01 & .03 \\
\hline F7 engaging in loving and intimate relationships & .86 & -.01 & -.05 & -.10 \\
\hline \multicolumn{5}{|l|}{ Community living activities $(\alpha=0.94)$} \\
\hline B1 getting from place to place throughout the community (transportation) & -.10 & .85 & .09 & -.03 \\
\hline B2 participating in recreation/leisure activities in community settings & .00 & .90 & -.05 & -.02 \\
\hline B3 using public services in the community & -.02 & .92 & -.03 & -.04 \\
\hline B4 going to visit friends and family & -.01 & .86 & .06 & -.04 \\
\hline B5 participating in preferred community activities (church, volunteer, etc.) & .12 & .75 & .01 & -.04 \\
\hline B6 shopping and purchasing goods and services & -.02 & .78 & -.00 & .07 \\
\hline B8 accessing public buildings and settings & .03 & .72 & .04 & .09 \\
\hline \multicolumn{5}{|l|}{ Activities for daily living $(\alpha=0.92)$} \\
\hline A1 using the toilet & .04 & -.02 & .90 & -.12 \\
\hline A4 eating food & .08 & .11 & .64 & .06 \\
\hline A6 dressing & -.04 & .01 & .91 & .05 \\
\hline A7 bathing and taking care of personal hygiene and grooming needs & -.06 & .09 & .77 & .06 \\
\hline \multicolumn{5}{|l|}{ Work $(\alpha=0.92)$} \\
\hline D2 learning and using specific job skills & .12 & .24 & -.05 & .60 \\
\hline D5 completing work-related tasks with acceptable speed & .03 & -.02 & -.03 & .92 \\
\hline D6 completing work-related tasks with acceptable quality & -.01 & -.05 & .05 & .97 \\
\hline
\end{tabular}

Note: $F .=$ Factor.

\subsection{Reliability}

Internal consistency, assessed by Chronbach's alpha coefficient varied between .92 and .94 for the four subscales (Table 2). The inter-item correlations ranged from .58 to .84 for the subscale 'Personal and social skills', .61-.77 for the subscale 'Community living activities', .66-.82 for the subscale 'Activities for daily living', and .73-.88 for the subscale 'Work'. All correlations were significant $(p<.001)$. Item-rest correlations (Table 3 ) displayed values ranging from .73 to .89. All values for Chronbach's alpha-if-item-deleted were lower or equal to the overall Chronbach's alpha, except for one item (i.e., D2). However, because the difference between the overall Chronbach's alpha and the Chronbach's alpha-if-item-deleted was very small (0.015) and other measures for this item were very good, item D2 was not removed.

\subsection{Construct validity}

In line with the first hypothesis, analyses revealed significant $(p<.001)$ positive correlations between .40 and .70 for the different subscales (Table 4). All correlations exceeded .50 , except the correlation between 'Personal and social skills' and 'Activities for daily living' ( $r=.40)$. With regard to the second hypothesis, all subscales were significantly ( $p$ s at least $<.05$ ) negatively correlated with the BI-indices, with small to large correlations ranging from -.08 to -.86 . The subscale 'Personal and social skills' was not significantly correlated with the BI mobility-index $(r=-.00)$. Correlations between the SIS subscales and the ELIDA were all significantly $(p<.001)$ positive, with small to large correlations ranging from .28 to .86. Testing the third hypothesis, correlations between three out of four SIS subscales and the need for behavioral support were significantly $(p<.001)$ positive, ranging between 0.10 and 0.47 . The correlation between the SIS-subscale 'Activities for daily living' and the need for behavioral support was not significantly different from zero. 
Table 3

Internal Consistency of the SIS1.0-NL $(N=1,303)$.

\begin{tabular}{|c|c|c|}
\hline & $r_{\text {ir }}$ & $\alpha_{\mathrm{id}}$ \\
\hline \multicolumn{3}{|l|}{ Personal and social skills $\left(\alpha=0.93 ; r_{F, D S T}=.73 ; r_{F, T S}=.71 ; r_{D S T, T S}=.80\right)$} \\
\hline C8 learning self-determination skills & .80 & .92 \\
\hline C9 learning self-management strategies & .79 & .92 \\
\hline E8 maintaining emotional well-being & .73 & .93 \\
\hline F1 socializing with the household & .76 & .93 \\
\hline F4 making and keeping friends & .77 & .92 \\
\hline F5 communicating with others about personal needs & .79 & .92 \\
\hline F6 using appropriate social skills & .76 & .93 \\
\hline F7 engaging in loving and intimate relationships & .75 & .93 \\
\hline \multicolumn{3}{|l|}{ Community living activities $\left(\alpha=0.94 ; r_{F, D S T}=.72 ; r_{F, T S}=.68 ; r_{D S T, T S}=.87\right)$} \\
\hline B1 getting from place to place throughout the community (transportation) & .82 & .93 \\
\hline B2 participating in recreation/leisure activities in community settings & .83 & .93 \\
\hline B3 using public services in the community & .84 & .93 \\
\hline B4 going to visit friends and family & .84 & .93 \\
\hline B5 participating in preferred community activities (church, volunteer, etc.) & .76 & .94 \\
\hline B6 shopping and purchasing goods and services & .80 & .93 \\
\hline B8 accessing public buildings and settings & .81 & .93 \\
\hline \multicolumn{3}{|l|}{ Activities for daily living $\left(\alpha=0.92 ; r_{F, D S T}=.86 ; r_{F, T S}=.91 ; r_{D S T, T S}=.93\right.$ ) } \\
\hline A1 using the toilet & .81 & .89 \\
\hline A4 eating food & .76 & .91 \\
\hline A6 dressing & .87 & .87 \\
\hline A7 bathing and taking care of personal hygiene and grooming needs & .81 & .89 \\
\hline \multicolumn{3}{|l|}{ Work $\left(\alpha=0.92 ; r_{F, D S T}=.48 ; r_{F, T S}=.45 ; r_{D S T, T S}=.81\right)$} \\
\hline D2 learning and using specific job skills & .78 & .93 \\
\hline D5 completing work-related tasks with acceptable speed & .86 & .86 \\
\hline D6 completing work-related tasks with acceptable quality & .89 & .84 \\
\hline
\end{tabular}

Note: $r_{\mathrm{ir}}=$ item-rest correlation; $\alpha_{\mathrm{id}}=$ Cronbach's alpha-if-item-deleted; $\mathrm{F}$ = frequency; DST = daily support time; TS = type of support.

\subsection{Criterion validity}

Criterion validity was examined by summing the subscales into one score and computing the correlation with the type of services individuals received in daily life. A significant Eta correlation of $.74(p<.01)$ for working and a significant Eta correlation of .71 $(p<.001)$ for living indicated that there was a strong positive correlation between the SIS-scores and the type of services individuals received.

Table 4

Construct validity.

\begin{tabular}{lcccc}
\hline & Factor 1 & Factor 2 & Factor 3 & Factor 4 \\
\hline Factor 2 $(N)$ & $.53^{* * *}(1216)$ & & & \\
Factor 3 $(N)$ & $.40^{* * *}(1213)$ & $.70^{* * * *}(1260)$ & $.54^{* * *}(1164)$ & \\
Factor 4 $(N)$ & $.63^{* * *}(1161)$ & $.63^{* * *}(1168)$ & $-.85^{* * *}(699)$ & $-.20^{* * * *}(611)$ \\
BI (total) & $-.08^{* * *}(654)$ & $-.44^{* * *}(699)$ & $-.86^{* * *}(699)$ & $-.25^{* * *}(611)$ \\
BI (A.D.L.) & $-.17^{* * *}(654)$ & $-.48^{* * *}(699)$ & $-.76^{* * *}(701)$ & $-.14^{* *}(613)$ \\
BI (mob.) & $-.00(656)$ & $-.36^{* * *}(701)$ & $.86^{* * *}(694)$ & $.40^{* * *}(606)$ \\
ELIDA & $.28^{* * *}(649)$ & $.66^{* * *}(694)$ & $.01(1260)$ & $.22^{* * *}(1176)$ \\
SIS Section 3B & $.47^{* * *}(1216)$ & $.10^{* *}(1265)$ & & $(126)$ \\
\hline
\end{tabular}

Note: Factor $1=$ personal and social skills, Factor $2=$ community living activities, Factor $3=$ activities for daily living, Factor 4 = work, BI (total) = Barhel Index; BI (A.D.L.) = Barthel Index for daily living activities; BI (mob.) = Barthel Index for mobility.

$$
\begin{aligned}
{ }^{*} p & <.05 . \\
p & <.01 . \\
p & <.001 .
\end{aligned}
$$




\subsection{Reliability and validity of four subgroups}

Results in the four subgroups generally support findings for the total sample of persons with other than intellectual disabilities. On the whole, reliability and validity analyses revealed satisfying results for all subgroups. Due to limited space, these results will not be discussed in detail here, but are available from the first author on request.

\section{Discussion}

The SIS is an assessment tool of support needs originally developed for people with intellectual disabilities. The supports and support needs constructs that underlie the SIS however suggest a more general applicability of the scale. In the perspective of equity and rationality in resource allocation, the usefulness of the instrument for people with other than intellectual disabilities is worth examining. This is even more relevant in the context of agencies addressing the needs of persons with disabilities at large and not just of one subgroup. Because the psychometric properties of the SIS have primarily been examined for people with intellectual disabilities, the present study aimed to evaluate the psychometric properties of the SIS for people with other than intellectual impairments. We found that a shortened version of the SIS represents a psychometrically sound tool to assess the support needs of persons with other than an intellectual disability.

The shortened version (SIS-NID) yielded four subscales (22 items) reflecting personal and social skills ( 8 items), community activity skills ( 7 items), activities for daily living ( 4 items) and work-related skills ( 3 items). The first subscale labeled 'Personal and social skills' comprises items from three subscales of the original SIS, namely 'lifelong learning activities' (i.e., C8, C9), 'health and safety activities' (i.e., E8) and 'social activities' (i.e., F1, F4, F5, F6, F7). These items focus mainly on communication and relational skills. Furthermore, some personal skills, namely learning self-determination skills and learning selfmanagement strategies are included. The second subscale labeled 'Community living activities' entails seven out of eight items of the subscale 'community living activities' of the original SIS. Only item B7 'interacting with community members' was not included after exploratory factor analysis. The third subscale labeled 'Activities for daily living' consists of four items of the subscale 'home living activities' of the original SIS, namely 'using the toilet' (A1), 'eating food' (A4), 'dressing' (A6) and 'bathing and taking care of personal hygiene and grooming needs' (A7), covering the basic daily living needs. The last subscale labeled 'Work' comprised three items of the original 'employment activities' scale. The items cover the accessibility of the work/job space and accommodations (D1), as well as completing workrelated tasks with acceptable speed (D5) and quality (D6). Further analyses displayed overall good results concerning internal consistency, content validity, construct validity and criterion validity for the total sample of persons with other than intellectual disabilities, as well as for four subgroups (i.e. persons with acquired brain injury, persons with sensory disabilities, persons with physical disabilities and persons with autism spectrum disorder).

Although the results for construct validity were generally in line with our expectations, some minor remarks should be noted. First, despite the presence of a clear association between support needs and adaptive behavior scales (Guscia et al., 2006; Harries et al., 2005; Thompson et al., 2002), only very low correlations emerged between 'Personal and social skills' and the total BI-score and the BI-score for daily living activities. However, in light of the content of the scales, this finding is not surprising because the items constituting the subscale 'Personal and social skills' may not directly relate to daily living activities. This explanation is supported by the fairly small correlation between the subscale 'Personal and social skills' and the other adaptive behavior scale, as compared to other correlations. Second, the correlation between behavioral support needs and daily living support needs $(r=-0.00)$ failed to reach significance. Additionally, the correlations between behavioral support needs and the other subscales are smaller than expected $(r=.01-.46)$. One explanation is that behavioral support needs are inherently different from overall support needs, as measured by the SIS. Insufficient validity of the behavioral scale, when administered for people with other than intellectual disabilities, may be another explanation.

Despite overall satisfying results of the study, results have to be considered in light of the following limitations. First, during the data collection, no user's manual was available, neither was there 
sufficient time to provide individual training for all interviewers. Although several measures were taken, this may have introduced some bias. Moreover, previous studies probing the inter-rater reliability of the SIS have underlined the importance of sufficient training (McLaughlin, Morin, Tassé, \& Thompson, 2008; Thompson et al., 2008). Second, the present study does not cover inter-respondent reliability (different respondents), inter-interviewer reliability (different interviewers), mixed interrater (different interviewers with different respondents) or test-retest reliability. Whereas studies with the original SIS assessing persons with intellectual disabilities yielded satisfying results for these reliability measures (McLaughlin et al., 2008; Morin \& Cobigo, 2008), similar studies have to be undertaken for the shortened version of the SIS. Third, adaptive behavior scales (i.e., Barthel, Elida) were only administered to a subset of clients, particularly the ones in need of the most support. This might have influenced the association with the SIS subscales. Furthermore, overall staff estimates of support (e.g., as adapted from the ICAP Service Level scores) may provide a more adequate indicator for criterion validity.

Despite these limitations, this study is the first large-scale study probing the psychometric properties of the SIS for people with other than intellectual disabilities. Taken together, we can conclude that the usefulness of a shortened version of the SIS within this population seems promising. The shortened version of the SIS provides a useful and psychometrically sound alternative for the assessment of support needs of persons with other than intellectual disabilities. On an individual level, the SIS provides an overview of the support needs of persons with other than intellectual disabilities. Similar to the original SIS for persons with intellectual disabilities, the shortened version can be used as an individual planning tool for persons with other than intellectual disabilities. On a macro-level, the shortened version of the SIS can be used for descriptive analysis of the support needs of all persons with other than intellectual disabilities, or be used as a tool for resource allocation. Nevertheless, further research is needed to replicate and extend these preliminary findings regarding the shortened version of the SIS (SIS-NID). Moreover, to ensure the use of the shortened SIS as a tool for individual support plans as well as allocation purposes, standard scores are needed in order to facilitate comparison of the results for people with other than intellectual disabilities. Finally, former research among persons with intellectual disabilities, as well as our experiences within this study, stresses the importance of the availability of a clear and well-written manual, with explicit guidelines concerning the use of the SIS. Similar guidelines as outlined in the manual of the original SIS, such as 4-year degree and several years of work experience with the target group for the interviewer, need of specific training concerning the use of the SIS, respondents have known the client for at least 3 months and observed the client in different settings (Thompson et al., 2004), must be taken into account when using the shortened version of the SIS.

\section{Acknowledgements}

Many thanks go to all the agencies supporting clients with other than intellectual disabilities. Thanks to the efforts of the staff and the clients we obtained valuable data for a large group of persons with other than I.D.

\section{References}

Brusselmans, W. (1992). De ELIDA-schaal. Estimation of Loss of Independence [The ELIDA-scale. Estimation of Loss of Independence]. Acta Physiotherapeutica, 47, 51-54.

Brusselmans, W. (1993). Validiteit en betrouwbaarheid van de ELIDA-schaal [Validity and reliability of the ELIDA-scale]. Liber Amoricum ter gelegenheid van het emeritaat van Prof. Dr. H. Claessens (pp. 65-76)

Buntinx, W. H. E. (2006). Schaal Intensiteit van Ondersteuningsbehoeften Handleiding [Supports Needs Intensity Scale. Manual]. Utrecht: NGBZ.

Buntinx, W. H. E. (2007). Rapportage Vlaamse normeringstudie van de Supports Intensity Scale (SIS-NL 1.0) (Rapport Vlaamse Normering SIS voor VAPH - 2007) [Report Flemish norm study of the Supports Needs Intensity Scale (SIS-NL 1.0) (Report Flemish norm study SIS for the Flemish Agency for Disabled Persons - 2007)]. Maastricht: UM-CAPHRI.

Buntinx, W. (2008a). The Dutch version of the Supports Intensity Scale. In R. L. Schalock, J.R.J.R. Thompson, \& M. J. Tassé (Eds.), Psychometric properties of the Supports Intensity Scale (pp. 6-10). Washington, DC: AAIDD.

Buntinx, W. (2008b). Dutch translation of the Supports Intensity Scale. In R. L. Schalock, J. R. Thompson, \& M. J. Tassé (Eds.), International implementation of the Supports Intensity Scale (pp. 15-16). Washington, DC: AAIDD. 
Buntinx, W., van Unen, F., Speth, W., \& Groot, W. (2006). The Supports Intensity Scale in the Netherlands: Psychometric properties and application in practice. Journal of Applied Research in Intellectual Disabilities, 19, 246.

Butterworth, J. (2002). From programs to supports. In R. L. Schalock, P. C. Baker, \& M. D. Croser (Eds.), Embarking on a New Century: Mental Retardation at the End of the 20th Century (pp. 83-100). Washington, DC: American Association on Mental Retardation.

Cohen, J. (1988). Statistical power analysis for the behavioral sciences (2nd ed.). Hillsdale, NJ: Lawrence Erlbaum Associates.

De Haan, R., Limburg, M., Schuling, J., Broeshart, J., Jonkers, L., \& Van Zuylen, P. (1993). Klinimetrische evaluatie van de Barthel-index, een maat voor beperkingen in het dagelijks functioneren. Nederlands Tijdschrift voor Geneeskunde, 37, 917-921.

Giné, C. (2008). Catalan translation of the Supports Intensity Scale. In R. L. Schalock, J. R. Thompson, \& M. J. Tassé (Eds.), Psychometric properties of the Supports Intensity Scale (pp. 7-8). Washington, DC: AAIDD.

Granger, C. V., Devis, L. S., Peters, M. C., Sherwood, C. C., \& Barrett, J. E. (1979). Stroke rehabilitation: Analysis of repeated Barthel Index measures. Archives of Physical Medicine and Rehabilitation, 60, 14-17.

Guscia, R., Harries, J., Kirby, N., Nettelbeck, T., \& Taplin, J. (2006). Construct and criterion validities of the Service Needs Assessment Profile (SNAP): A measure of support for people with disabilities. Journal of Intellectual \& Developmental Disability, 31, $148-155$.

Harries, J., Guscia, R., Kirby, N., Nettelbeck, T., \& Taplin, J. (2005). Support needs and adaptive behaviors. American Journal on Mental Retardation, 110, 393-404.

Hu, L., \& Bentler, P. M. (1999). Cutoff criteria for fit indexes in covariance structure analysis: Conventional criteria versus new alternatives. Structural Equation Modeling, 6, 1-55.

Jöreskog, K., \& Sörbom, D. (2005). LISREL 8.72. Lincolnwood: Scientific Software Inc.

Kuppens, S., Bossaert, G., Buntinx, W., Molleman, C., Van den Abeele, A., \& Maes, B. (submitted for publication). Factoral validity of the Supports Intensity Scale (SIS).

Lamoureux-Hébert, M., \& Morin, D. (2008). French translation of the Supports Intensity Scale. In R. L. Schalock, J. R. Thompson, \& M. J. Tassé (Eds.), International implementation of the Supports Intensity Scale. Washington, DC: AAIDD.

Luckasson, R., Borthwick-Duffy, S., Buntinx, W. H. E., Coulter, D. L., Craig, E. M., Reeve, A., et al. (2002). Mental retardation: Definition, classification and systems of supports (10th ed.). Washington, DC: American Association on Mental Retardation.

Maes, B., Bossaert, G., Kuppens, S., \& Buntinx, W. (2008). Inschaling van bijzondere doelgroepen met de Supports Intensity Scale (SIS-NL 1.0) [Assessing special focus groups with the Supports Intensity Scale (SIS-NL 1.0)]. Leuven: Katholieke Universiteit Leuven, Centrum voor Gezins- en Orthopedagogiek.

Mahoney, F. I., \& Barthel, D. W. (1965). Functional evaluation: The Barthel Index. Maryland State Medical Journal, $14,61-65$.

McLaughlin, C., Morin, D., Tassé, M. J., \& Thompson, J. R. (2008). The English version of the Supports Intensity Scale. In R. L. Schalock, J. R. Thompson, \& M. J. Tassé (Eds.), Psychometric properties of the Supports Intensity Scale (pp. 5-). Washington, DC: AAIDD.

Morin, D., \& Cobigo, V. (2008). The French version of the Supports Intensity Scale. In R. L. Schalock, J. R. Thompson, \& M. J. Tassé (Eds.), Psychometric properties of the Supports Intensity Scale (pp. 3-4). Washington: AAIID.

Nunnally, J. C., \& Bernstein, I. H. (1994). Psychometric theory. New York: McGraw-Hill.

Schalock, R. L., Thompson, J. R., \& Tassé, M. J. (2008). International implementation of the Supports Intensity Scale. Washington: AAIID.

Thompson, J. R., Hughes, C., Schalock, R. L., Silverman, W., Tassé, M. J., Bryant, B. R., et al. (2002). Integrating supports in assessment and planning. Mental Retardation, 40, 390-405.

Thompson, J. R., Bryant, B. R., Campbell, E. M., Craig, E. M., Hughes, C. M., Rotholz, D. A., et al. (2004). Supports Intensity Scale. Users' Manual. Washington: American Association on Mental Retardation.

Thompson, J. R., Tassé, M. J., \& McLaughlin, C. A. (2008). Interrater reliability of the Supports Intensity Scale (SIS). American Journal on Mental Retardation, 113, 231-237.

Thompson, J. R., Bradley, V. J., Buntinx, W. H. E., Schalock, R. L., Shogren, K. A., Snell, M. E., et al. (2009). Conceptualizing supports and the support needs of people with intellectual disabilities. Intellectual Disability, 47, 135-146.

Van der Putten, J. J. M. F. , Hobart, J. C., Freeman, J. A., \& Thompson, A. J. (1999). Measuring change in disability after inpatient rehabilitation: Comparison of the responsiveness of the Barthel Index and the Functional Independence Measure. Journal of Neurology, Neurosurgery and Psychiatry, 66, 480-484.

Verdugo, M., Arias, B., Ibanèz, A., \& Gómez, L. (2006). Validation of the Spanish version of Supports Intensity Scale. Journal of Applied Research in Intellectual Disabilities, 19, 274.

Vlaams Agentschap voor Personen met een Handicap. (n.d.). The VAPH. Retrieved February 5, 2009, from http://www.vaph.be/vlafo/ view/nl/204713-en.html. 